\title{
Spanish-Language Community Radio as a Resource for Health Promotion Campaigns Targeted to Farmworkers and Recent Immigrants
}

\author{
Edward Kissam, Jo Ann Intili, and Anna Garcia
}

Radio Bilingue

\begin{abstract}
This report describes findings from recent audience research on the impact of health promotion campaigns conducted by Radio Bilingue, a Spanish-language community public radio network. The discussion includes estimates of audience size and analysis of the station's ability to reach the population targeted in the health promotion campaigns: low-literate farmworkers, recent immigrants, and the parents of pre-school age children. The authors conclude that station identity and communication style play a crucial role in catalyzing listeners' discussion of health topics with family members, friends, neighbors, and co-workers. This, in turn, has important implications for developing health promotion strategies and designing media campaigns directed to Latino immigrant populations.
\end{abstract}

(C) 2003 Californian Journal of Health Promotion. All rights reserved.

Keywords: Farmworkers, immigrants, Latinos, media campaigns

\section{Introduction}

A challenge facing health promotion efforts in California is that the Latino sub-populations who are targeted in campaigns are often very limited in English and educationally disadvantaged. This seriously limits the effectiveness of campaigns built around printbased materials. Thus, Spanish-language radio deserves consideration as an option for reaching such population groups.

In this article, we review the role played by a Spanish-language community public radio network, Radio Bilingue, in a wide range of health promotion efforts directed toward Latinos in rural California. Traditional public broadcasting is most successful in reaching elite audiences and thus has marginal utility as a resource for health promotion campaigns targeting educationally and socio-economically disadvantaged populations. Radio Bilingue, however, has a different focus, as its mission and programming are oriented toward reaching a "downscale" demographic group consisting primarily of farmworkers, recent immigrants, and other Latino families living in rural areas or urban areas such as Bakersfield, Fresno, and Modesto. Our analysis is based primarily on the findings from a survey of Spanish-speaking residents of the 11 rural California counties currently served by the station.

\section{Radio Bilingue's Service Areas and Potential Audience}

Radio Bilingue is a network of Spanishlanguage public radio stations making up about one-third of the national Latino public radio system. Radio Bilingue serves three rural regions of California with concentrated populations of Latinos in the San Joaquin Valley, Imperial County, and Monterey/Santa Cruz/San Benito county area.

The largest of the station's service regions is the San Joaquin Valley. The San Joaquin Valley service area stretches from Stanislaus County in the north through Kern County in the South. Standard Hispanic radio market resource identifies five distinct markets in this region and estimates the population of Hispanic listeners 12 years of age and older in the area as numbering 744,800 . Thus, considered as a single market, 
Radio Bilingue's San Joaquin Valley service area would rank as the 7th largest Hispanic radio market in the country (Arbitron, 2002). The second largest of the service regions, with a population of about 220,000 Hispanic radio listeners 12 year of age and older is the Monterey/Santa Cruz county region. This is the 26th largest Hispanic Radio market in the country. The smallest of the service regions is Imperial County, with a Hispanic population of about 115,000 . Thus, all in all the station's signal reaches areas with more than 1 million teens and adults living in Spanish-speaking households. As a whole, Radio Bilingue's service area would rank as the $6^{\text {th }}$ largest Hispanic market in the country-below Chicago and slightly above Houston-Galveston.

Radio Bilingue's programming is multi-lingual (in Spanish, English, Mixtec, and Hmong) in order to reach the main ethnic minority populations in the area. However, most of the station's programming is in Spanish and most listeners' primary language is Spanish. It would, nonetheless, be a mistake to underestimate the language diversity of the station's listeners who include: English-dominant Mexican-Americans whose Spanish is limited, long-time Mexican immigrants and native-born Latinos who are bilingual, Mexican and other Latino immigrants whose English is limited, and indigenous Oaxacan immigrants who speak Mixtec, Triqui, Zapotec or another indigenous Mexican language. Many of the indigenous Oaxacan listeners are bilingual in Spanish and their native language but a significant minority (mostly women, but, also, some men) are very limited in Spanish. Very few are trilingual.

\section{Research Methods}

In this article, we report findings from a recent large audience research survey we conducted, the Tri-Valley Tobacco/California Endowment Survey (TVT/TCE). The TVT/TCE survey was conducted during May-August, 2002. We supplemented this analysis with more limited reference to findings from a 2002 Kern County Proposition 10-related survey conducted in September-October, 2002 and similar surveys conducted in Tulare and Fresno counties (see Table 1).
In designing the TVT/TCE survey, we decided to concentrate on conducting a relatively largescale survey of a population from which Radio Bilingue's core audience is drawn - lowincome, Spanish-speaking persons, primarily immigrants, but, also, native-born low-income Latinos. The large sample size for the TCE/TVT survey $(\mathrm{N}=602)$ made it possible for us to look at differential impacts among different subpopulations of Radio Bilingue's core audience and, at the same time, look to see what differences, if any, there might be between the treatment group (station listeners) and a comparison group (non-listeners) in the survey sample. In designing the KCP10 survey we screened potential survey respondents to assure they were part of the target population for the Kern County Proposition 10 campaign (that is, parents or caregivers of pre-school age children or pregnant women).

\section{TVT/TCE Sampling Design}

The TVT/TCE study focused on 11 of the 13 rural counties identified by Radio Bilingue as primary counties where the campaign would be implemented. The KCP10 survey study focused on an additional county (Kern) which was not part of the TVT/TCE research. Our use of an intercept approach was dictated both by analytic issues stemming from the sample bias inherent in using traditional survey methods (e.g., random-digit dialing telephone surveys to survey Radio Bilingue's core audience, as well as by the practical constraints of budget (which made it infeasible to conduct door-to-door household surveys). We have concerns about analytic issues related to sample bias using phone surveys because only $18-30 \%$ of the households in this population do not have a listed telephone (although some individuals have unlisted wireless phones). Mail surveys were rejected out of hand as a culturally inappropriate and statistically flawed approach to surveying this low-literate population; the most serious problems in decennial census undercount of minorities, for example, stem from inadequate mailing lists which systematically underrepresent minorities, especially immigrants. 


\section{Venues for the Intercept Surveys: Flea Markets}

Flea markets (remates, tianguis) were identified as being the primary venue for conducting the intercept interviews. They fit the criterion for generating a broad range of interviews (considering gender, urban/rural location, ethnicity, and income Latinos). Interviews were conducted at the major remates in each area. Subsequent analysis of survey data, reported in this paper, confirmed that the sample of survey respondents appears to be highly representative of the population targeted by the station's health promotion campaign (defined as Spanishspeaking families, especially farmworkers and recent immigrants).

For the TVT/TCE intercepts, we identified the major remates (flea markets) in four of Radio Bilingue's station service areas (KSJV-Fresno; KMPO-Modesto, KHDC-Salinas, and KUBO-El Centro). We followed the same procedure for the 2002 Kern County study where we focused on service provided by KTQXX-Bakersfield to Kern County listeners and in the Fresno County 2001 and 2002-2003 surveys.

In the Fresno area TVT/TCE survey we supplemented our flea market intercept interviews with modest numbers of interviews at the Fulton Mall (2\% of the total sample) and at the Fashion Fair Mall (6\% of the total sample), to make sure we were enabling interviews for moderate income listeners. In the southern San Joaquin Valley area interviews were conducted on peak shopping days at the Selma Flea Market, the Cherry Auction, the Madera Flea Market, the Cutler-Orosi Flea Market, the Riverdale Flea Market, and the Fresno Fair Grounds Flea Market. In the Modesto area, interviews were conducted at the Ceres Flea Market. In the Salinas and the El Centro areas, we interviewed attendees at the only flea market in the community.

\section{The TVT/TCE Survey Instrument}

The survey instrument was designed as part of our overall audience research strategy which is intended to facilitate meta-analysis of data from different studies. Thus, the survey instrument contains a sub-set of "standard" questions used to generate a profile of each respondent which can, then, be used to analyze responses for demographic sub-populations (e.g., young adult males $<25$ years of age speaking little or no English) or to generate profiles for sub-groups of listeners (e.g., those who recall some of the TCE-funded programs vs. those who do not).

The survey instrument also includes several standardized queries as part of the station's "general" audience research - a question regarding Spanish-language radio listening habits (Q. 3), regarding "favorite" stations (Q. 4), "most liked" and "least liked" features of station service (Q. 8 and 9) and "particularly liked" programs/hosts (Q. 10), and some health habits questions (Q23 through Q25).

The survey instrument is designed to generate several alternative measures of exposure to the station's health-related programming and, specifically, to program elements which constituted the radio intervention strategies being used. Thus, the survey provides what is, essentially, a curriculum-referenced indication of the impact of the health promotion campaign.

\section{Findings Regarding Market Penetration}

Our findings about Radio Bilingue's market penetration within the population of low-income Spanish-speaking households are presented in Table 1 below.

Table 1

Radio Bilingue Market Penetration

\begin{tabular}{|l|l|c|}
\hline \multicolumn{1}{|c|}{$\begin{array}{c}\text { Survey and Number of } \\
\text { Respondents }\end{array}$} & \multicolumn{1}{|c|}{ Population Surveyed } & $\begin{array}{c}\text { \% of Respondents Who } \\
\text { Are Regular Station } \\
\text { Listeners }\end{array}$ \\
\hline $\begin{array}{l}2002 \mathrm{TCE} / \mathrm{TVT} \\
(\mathrm{N}=602)\end{array}$ & $\begin{array}{l}\text { Predominantly low-income } \\
\text { Spanish-speaking, immigrants }\end{array}$ & $61 \%$ \\
\hline
\end{tabular}




\begin{tabular}{|l|l|c|}
\hline $\begin{array}{l}\text { 2002 Kern Co. Prop. 10 } \\
(\mathrm{N}=111)\end{array}$ & $\begin{array}{l}\text { Predominantly low-income } \\
\text { Spanish-speaking, parents of } \\
\text { children 0-5 }\end{array}$ & $59 \%$ \\
\hline $\begin{array}{l}\text { 2001 Fresno Co. Prop 10 } \\
(\mathrm{N}=97)\end{array}$ & $\begin{array}{l}\text { Spanish-speaking parents of } \\
\text { children 0-5 }\end{array}$ & $63 \%$ \\
\hline $\begin{array}{l}2002-2003 \text { Fresno Co. Prop. 10 } \\
(\mathrm{N}=81)\end{array}$ & $\begin{array}{l}\text { Predominantly low-income } \\
\text { Spanish-speaking parents of } \\
\text { children 0-5 }\end{array}$ & $60 \%$ \\
\hline
\end{tabular}

In each of the surveys, an additional $10-20 \%$ of the respondents say they listen to Radio Bilingue infrequently. We do not consider these to be part of the station's core audience; our current definition of the core audience as persons who listen to the station at least once per week is consistent with industry definitions of "weekly cume." Moreover, given the nature of radio listeners "surfing," having heard a station infrequently tells little about listeners' preferences, and the impacts of programming are likely to be negligible among these peripheral listeners.

\section{The Survey Samples, Station Listeners, and Non-Listeners}

An important strand of the audience and program research effort has been to assess the extent to which Radio Bilingue reaches different sub-populations or audience segments among its Spanish-speaking listeners.

Where census data and standard surveys tend to under-represent low-income Latinos and immigrants, farmworkers, and teenage males (Kissam, Gabbard, \& Martin, 1993; Kissam \& Jacobs, 2002), our remate-based sampling approach probably under-represents highincome Latinos working in professional or technical occupations, older middle-class homemakers, and English-speaking Chicano/a teenagers and adults. Thus, the survey sample should be considered to represent quite successfully represent the Radio Bilingue core service population which is made up primarily of low-income Spanish-speaking first generation and second-generation bilingual immigrants but not to represent all Hispanics in the service area or even all Spanish-speaking Hispanics.
For the purposes of the current survey we considered questions about respondents' educational attainment and family income too intrusive, so we used instead, several surrogate indicators of socioeconomic status. These include: occupation, home language, fluency in English, Spanish, or other native language, household size, and length of time in the United States.

\section{Profile of the Survey Population, Station Listeners, and Non-Listeners}

In this section we describe the overall TVT/TCE survey population, remate attendees, and compare Radio Bilingue listeners to the overall population and to non-listeners

\section{Occupational Profile}

The majority of the TCE/TVT Survey respondents are employed in agriculture $-47 \%$ as field workers or in general farmwork (e.g., as tractor drivers or irrigators), $3 \%$ in livestock, poultry production, or dairy work, $2 \%$ in packing sheds of processing, and $1 \%$ as farm labor contractors or supervisors). Thus, the sample provides a useful tool for generating insights into the station's service to a key target population for Latino health promotion.

Another $6 \%$ of the survey respondents worked in other low-paying immigrant-dominated occupational clusters including restaurant work, day care and home health care, gardening, and flea market/ remate selling. The survey respondents also include a significant number of Latinos (17\% of the total sample) employed in a range of blue collar or low-paid white collar occupations - in construction, other trades such 
as plumbing, plant mechanics, equipment installers, maintenance and janitorial work, truck driving, and in retail sales.

One in ten of survey respondents $(10 \%)$ worked in a professional, managerial, technical, or administrative job. We included in this category immigrant entrepreneurs who owned stores or other small businesses and community outreach workers who are, within the context of rural California life, among the socioeconomic elite.

Finally, the survey respondents included a range of persons not in the labor force: students $(5 \%)$, home makers $(7 \%)$, and retired or disabled persons $(3 \%)$.

Farmworkers and other agricultural workers are somewhat more likely than the overall TVT/TCE survey population to be regular Radio Bilingue listeners $(63 \%$ of the farmworkers and workers in other low-paying immigrant occupations vs. $61 \%$ overall) while professional, managerial, technical employees and students are slightly less likely to be regular listeners (51\% listen regularly vs. $61 \%$ overall

The occupational profile of Radio Bilingue listeners is unusual in public broadcasting, in that the station has many in "low-skill", immigrant-dominated occupations which have few educational requirements or Englishlanguage communication requirements while, at the same time, reaching a group we refer to as the "Latino blue-collar elite" — outreach workers, teachers, and other socially-involved persons in the community.

\section{Language Profile}

Language use and preferences among California Latinos is becoming increasingly complex and the survey sample is representative of state trends in this regard. Table 2 below shows the language profiles of Radio Bilingue's regular listeners and non-listeners within the survey population.

Table 2

Language Profile of Radio Bilingue Listeners and Non-Listeners in TVT/TCE Survey*

\begin{tabular}{|c|c|c|}
\hline Language Profile & $\begin{array}{c}\text { Language Profile of the } \\
\text { Radio Bilingue Audience }\end{array}$ & $\begin{array}{c}\text { Language Profile of the } \\
\text { Overall Sample }\end{array}$ \\
\hline Speaker of Indigenous Language & & $2 \%$ \\
\hline Very limited Spanish and English & $3 \%$ & $7 \%$ \\
\hline Some Spanish & $7 \%$ & \\
\hline Primary Language Spanish & & $44 \%$ \\
\hline Very Limited English & $52 \%$ & $23 \%$ \\
\hline Some English & $23 \%$ & $3 \%$ \\
\hline Some Spanish & $4 \%$ & $22 \%$ \\
\hline Bilingual Spanish/English & $11 \%$ & \\
\hline
\end{tabular}

* Source: Q. 19-20 and Q. 6

The differences in the representation of different language groups in the survey population overall and among the Radio Bilingue listenership reflects different market penetration within these different population segments. There is a significant correlation between language profile and listenership among some of the sub-groups of listeners. Persons who speak an Mexican indigenous language (e.g., Mixtec, Triqui) in their home are more likely than other Latinos to be regular Radio Bilingue listeners (with $67 \%$ of the indigenous Mexican respondents being regular listeners vs. $61 \%$ of the overall survey population). Conversely, English-speaking individuals are generally less likely to listen to the station than limited-English persons. For example, only $51 \%$ of the English-Spanish bilingual survey respondents are regular Radio 
Bilingue listeners as compared to $61 \%$ of the Spanish-dominant limited-English persons). However, the small group of primary-language English/some Spanish listeners were more likely to listen to Radio Bilingue.

It should be noted that many of the households in this population are multi-lingual. We asked what languages were spoken at home by survey respondents. While $96 \%$ said that Spanish was spoken in their household, 10\% (virtually all of the indigenous language respondents) also spoke their native language at home. Nearly two-thirds of the households (64\%) have children living in them. In households with school-age children there is likely to be at least some English spoken, even when English is the 3rd language of the household.

\section{Immigration Profile of Survey Respondents and Station Listeners}

Because the TVT/TCE sampling methodology was designed to generate the best possible crosssection of low-income Spanish-speaking persons in the Radio Bilingue service area, the survey has a relatively low proportion of U.S-born individuals $(8 \%)$, a slightly elevated proportion of Mexican immigrants (90\%) and a small proportion of Central American immigrants (2\%). Table 3 below shows length of time in the U.S. for the overall TV/TCE survey respondents who are immigrants as compared to those who are regular station listeners.

Table 3

Immigrant Population and Radio Bilingue Listeners' Length of Time in The U.S.*

\begin{tabular}{|c|c|c|}
\hline Time in U.S. & All Survey Respondents & Regular Station Listeners \\
\hline Recent Immigrants & $26 \%$ & $25 \%$ \\
\hline$<3$ years & $12 \%$ & $9 \%$ \\
\hline 3-5 Years & $14 \%$ & $16 \%$ \\
\hline Long-Term Immigrants & $74 \%$ & $75 \%$ \\
\hline 6-10 years & $18 \%$ & $16 \%$ \\
\hline 11-25 years & $47 \%$ & $49 \%$ \\
\hline$>25$ years & $9 \%$ & $10 \%$ \\
\hline
\end{tabular}

* Source: Q. 24 and Q. 6

The data in Table 3 suggest that Radio Bilingue does a good job of reaching even the most recently-arrived immigrants to California. However listenership is somewhat lower among the very recent immigrants $(<3$ years in the U.S) but then higher among the 3-5 year cohort It seems that, new immigrants become aware of Radio Bilingue within a few years of arriving in the area.

\section{Standard Demographic Profile - Gender and Age}

Standard demographic measures, race, gender, and age, do not serve as an adequate framework for understanding the diversity of the rural Latino population in California or in other areas of the United States nor do they provide an adequate basis for audience research to assist Radio Bilingue in meeting the challenges inherent in responding to the needs and radio listening preferences of such a diverse population. Nonetheless, they are important components of such analyses; but it must be stressed that there are a number of distinct and important sub-groups within each general "quadrant" of the demographic sub-groups of the station's Latino service population.

\section{Gender}

The male/female ratio is skewed in the population of Spanish-speaking Mexican-origin immigrants in Radio Bilingue's service area because of the large surplus of male transnational migrants who come to the area to work in farmwork, leaving wives, children, and young single women behind in migrant-sending villages of Mexico. Thus, it appears that the TVT/TCE survey sampling approach may have 
skewed the gender distribution of respondents because there are so many young men who are recently-arrived farmworkers that frequent the remates. Slightly more than two-thirds of TVT/TCE survey respondents (71\%) are men and slightly less than one-third (29\%) are women. Men and women in the survey sample appear to be equally likely to listen to Radio Bilingue, although based on previous surveys, we believe the overall audience is skewed slightly toward women. This skew is in part due to the fact that farmworkers (the majority of whom are men) have less opportunities to listen to the station and in part because of substantial listenership among older immigrant women.

\section{Age Distribution of Listeners and Non- Listeners in the Survey Populations}

Table 4 below shows the age distribution of TVT/TCE Survey respondents and of the regular station listeners in each of the station outlet areas in the study.

Table 4

Age of Regular Station Listeners and Non-Listeners*

\begin{tabular}{|l|c|c|c|c|}
\hline \multicolumn{1}{|c|}{ AGE } & Non-Listeners & \multicolumn{3}{c|}{ Regular Listeners } \\
\hline \multicolumn{1}{|c|}{ Area==== } & Overall & Fresno & Salinas & El Centro \\
\hline$<25$ years & $32 \%$ & $21 \%$ & $26 \%$ & $4 \%$ \\
\hline $25-34$ years & $34 \%$ & $36 \%$ & $45 \%$ & $7 \%$ \\
\hline $35-44$ years & $22 \%$ & $25 \%$ & $26 \%$ & $29 \%$ \\
\hline $45+$ years & $11 \%$ & $19 \%$ & $3 \%$ & $61 \%$ \\
\hline
\end{tabular}

* Source: Q. 2

The mean age of TV/TCE survey respondents who regularly listen to Radio Bilingue is 33.9 years while the mean age of the survey respondents who are non-listeners is 30.8 years, primarily due to the lower level of listenership among teens and young adults $<25$ years of age and the higher level of listenership among persons 45 years of age or older in the surveyed population. The basic challenge in programming and in audience research in these areas, and, generally, throughout the station's service area is that there are two divergent sub-groups within this overall demographic segment of Latino youth and young adults: 1) Chicano/Chicana youth who are English-dominant or bilingual and 2) recently-arrived monolingual immigrants. The station is airing youth-oriented programs in English and a mix of English and Spanish in the Salinas, Bakersfield, and El Centro station outlets but we do not have adequate data to adequately assess listenership among this audience segment (in part because these youth do not frequent the remates as much as immigrants and, thus, make up a small portion of the survey sample).

\section{Families with Children}

Two-thirds (64\%) of the survey respondents have children who live with them. As we discuss later, throughout the station's audience research program, there is evidence that programming on family communication, relationships, and the challenges of parenting in a cross-cultural context are in high demand. Since about one in five of the immigrant households with children are recently arrived immigrants, issues related to access to health care and children's health issues are likely to be unfamiliar to them. The California immigrant population includes, in general a high proportion of households of "mixed" immigration status (Fix and Zimmerman, 1999); while the Public Use Microdata Set (PUMS) files from Census 2000 are not yet available to determine the household immigration status profile for Mexican immigrants in the rural areas served by Radio Bilingue we know this is a common occurrence. This is important, in the current context, because it means that health care access issues are also problematic for most of the rural immigrant 
families from Mexico who have been in California for less than 15 years.

\section{Station Identity as a Determinant of Health Promotion Effectiveness}

Commercial audience research classifies the format used by almost all the stations in rural California as "Mexican regional" format. This taxonomy does not, however, provide an adequate framework for understanding the gradations of taste which draw listeners to one specific station within the generic format or another. In the TVT/TCE and Proposition 10related research we sought to gain deeper insights into the target population's perceptions about Radio Bilingue and other popular Spanishlanguage stations.

Station identity is an important concern in media campaigns because a target populations' acceptance of health promotion messages and the subsequent impact of such messages had on their attitudes about health-related issues, their aspirations, and, ultimately, their health-related behavior is related to perspectives about the message source and its social identity. Especially among groups such as Latino immigrants to California there is likely to be a gradient of message acceptance/rejection based on perceptions as to whether the message comes "from people like us" or from more distant social groups. Therefore, in the TCE/TVT survey we asked station listeners what they most liked and least liked about Radio Bilingue's programming to determine if the station was likely to be recognized as a "preferred" message sources, as well as to secure guidance for programmers in their ongoing efforts to constantly improve the quality of the station's service to the community.

\section{What Listeners Like Most and Least About Radio Bilingue}

Radio Bilingue has conveyed to its listeners its own sense of its identity as a populist institution. One listener commented for example, "They tell the truth. They've very warm. They treat people well" (Dicen la verdad. Son sinceros. Muy amables. Tratan bien a la gente). Another comment was, "They help our community and make me feel like they care about the listeners."
Another listener commented that what they liked was "their style."

Several listeners also distinguished Radio Bilingue's style from that of commercial stations. One listener for example referred to the station's programming as something they felt they could let their children listen to; another said that commercial stations were "raw/crude" (crudo) in contrast to Radio Bilingue which "spoke nicely" (hablan bien). Others contrasted Radio Bilingue with stations which are "vulgar/obscene" (groseros) or spoke approvingly of the station's on-air personnel not using "bad words".

There is support among Radio Bilingue listeners for the station's linguistic and thematic diversity. There is particularly strong support among indigenous-origin listeners for the Mixtec programming, both the talk segments and the chilenas but even some of the "mainstream" Spanish-speaking Latino listeners say they like the station's diversity, both the mix of information/talk programming, music, and the different types of music aired. There is also support for the Tejano-oriented show "Arriba El Norte". Other specific shows highlighted in listener comments include the cultural program, "Mexico de Mis Andanzas", "La Placita Bilingue", and "Rockin' Da House".

Comments from a range of listeners indicate appreciation of the station's role as a resource for expressing and sustaining cultural identity from presenting "Latino perspectives" on news and public affairs, to maintaining listeners' links with their country of origin. For example, one listener spoke of the cultural program as being good for his mental health, as otherwise he would become lonely for Mexico. Another listener pointed to Radio Bilingue's links with Mexican stations as one important aspect of this cultural role.

Aspects of the station's information programming which were highlighted in listeners' comments about what they most liked included positive comments about the station's news service, Noticiero Latino, about the public affairs programming, Linea Abierta, about 
programming on immigration issues, programming about farmworkers' rights, and about Mexican and indigenous culture. Information on immigration is valuable to many of the listeners. One said, for example, that without Radio Bilingue he would not know what he would do to find out about changes and regulations.

What seems a paradox at first glance, the idea that support for cultural continuity is consistent with cultural resiliency, with learning how to function effectively in a new cultural and sociopolitical setting - is a useful insight about Radio Bilingue's role in helping immigrants navigate between their "old" lives and new environments. One of the challenging aspects of the ongoing research is to understand how the "virtual agora" Radio Bilingue creates can contribute to the evolution of "comunidades sin fronteras" the social space in which so many California immigrants actually live their lives (Rosenau 1993).

One-third of the specific comments (33\%) about what station listeners liked best about the station referred to its informational, sometimes referred to as "educational" programming. About one in five of the comments about the station's information/educational role as being one which the listener most liked referred specifically to health-related programming. It is not surprising to hear that elite public broadcasting audiences appreciate informational or "educational" programming but this is not generally recognized as an interest of educationally disadvantaged, low-income radio listeners.

An inevitable consequence of Radio Bilingue's efforts to respond to the diversity of Latino communities in its service area is that some programs are very popular in some audience segments while they are, at the same time, unpopular with other listeners. A few listeners criticized the station for mixing English into a predominantly Spanish-language program environment; this was particularly disturbing to some listeners when on-air personnel mixed Spanish and English in the same segment of discourse. Some guests on talk shows were also criticized by some listeners when they were not fully proficient in Spanish. The station's dilemma is, in part, because cultural stylistic cues generate both positive and negative reactions, depending on the listener's selfdefined identity/social allegiances. In the case of the station's Tejano-oriented program, "Arriba el Norte" there is, for example, divided opinion. The program is very popular with Tejanos and very unpopular with some of the very limited-English Mexican immigrants , in part because of the host's linguistic style. This is also the case with the youth-oriented programming. At the same time, other listeners specifically highlighted the station's bilingual programming as a feature they particularly liked. There were also a few listeners who objected to programming in Hmong and Mixtec; at the same time, many Mixteco listeners said they thought the station should air more programming in Mixtec. Other indigenous listeners said they wished Radio Bilingue would begin including programming in their native languages (Triqui and Zapotec were those specifically mentioned), either as part of "La Hora Mixteca or as separate programs. Even among Mixtec-speaking listeners there was some criticism of on-air show hosts for not speaking Mixtec well enough. This is not a surprising concern given the linguistic diversity of the Sierra Mixteca.. Secondary Audiences and the Role of
Community Dialogue in Health Promotion

Many of the station's regular listeners discuss the health programming they have heard with others. Two-thirds $(65 \%)$ of the regular listeners who had heard the station's health programming said that they had discussed at least some of the health topics addressed in the programming with others close to them such as family members, friends, co-workers, or neighbors.

This indicates that one facet of Radio Bilingue's intervention is not only to present listeners with information relevant to key issues but, also, to engage them in thinking about the programming and discussing it with others.

There are two related, but distinct, reasons why this is an important aspect of the station's production and programming strategy. The first reason is that such discussion generates 
"secondary" audiences and thus amplifies the overall exposure/impact of pro-social programming. The second, and even more compelling reason, is that listeners' active engagement in re-formulating the "educational messages" conveyed by the station's programming catalyzes their own process of learning while, at the same time, presenting a means to "customize" the basic source message within the domain of a particular social network.

The overall proportion of listeners who reported talking about programming with others, together with comments about the ways in which programming was "useful" to listeners, such as in discussing issues about safe sex with children or co-workers, diabetes management with parents, access to health care, indicates that Radio Bilingue's health programming can provide a vehicle to catalyze community dialogue. The station's role in generating such dialogue is different in kind from its role in communicating directly with individual listeners. What this implies for community-level and regional health promotion efforts is that Radio Bilingue should be seen as a resource for changing community perspectives, the level of attention given to one health-related issue or another. Currently, most of station listeners' talk about health-related programs takes place within the family networks. Deliberate campaign design and programming strategies can be forged to extend the current dialogue into listeners' other social networks such as workplace networks of co-workers and hometown village associations.

\section{Listener Priorities and Health Impacts}

The audience research so far has shown that Radio Bilingue's issues-oriented programming reaches and impacts most, but not all, listeners. From half to three-quarters of the listeners interviewed in each study have heard some of the health-related programming we ask them about in the course of evaluating a specific project. Mathematically, the chance a listener has heard any specific show is lower than the chance they have heard programming related to a general thematic strand or "campaign".

Radio listeners' recall of the specific programming they have heard is imperfect but we sought to construct survey questions which are anchored to specific topics or personalities. However, our measures of listener exposure to different elements of different campaigns seem to reflect "active recall" more than simple exposure. That is, recall of messages seems to be affected by whether the theme is perceived by the listener to be relevant to their lives, or to the lives of people close to them. The fact that recall has subjective aspects to it has some practical utility for the purposes of evaluation because there is some assurance that the listener who reports hearing a particular program segment has actually been affected by it becoming more informed, having a previous messages reinforced, or having been presented a new perspective.

Table 5 below provides estimates of the proportion of regular station listeners in the different survey samples who heard programming in each of several health-related areas:

Table 5

Listener Recall of Health-Related Programming

\begin{tabular}{|c|l|c|}
\hline $\begin{array}{c}\text { Study and Sample Program } \\
\text { Segments }\end{array}$ & Topics/Issues where Specific Recall Tested & $\begin{array}{c}\text { \% Listeners } \\
\text { Who Remember } \\
\text { Hearing Specific } \\
\text { Program Segments }\end{array}$ \\
\hline $\begin{array}{c}\text { TCE/TVT-Linea Abierta Satelite } \\
\text { (heard 1 of 6 sample segments) }\end{array}$ & $\begin{array}{l}\text { STD's, air pollution, youth depression, } \\
\text { glaucoma, Binational Health Week }\end{array}$ & $33 \%-49 \%$ \\
\hline TCE/TVT-Local-KSJV & STD's, the importance of translation for & $37 \%-68 \%$ \\
\hline
\end{tabular}




\begin{tabular}{|c|l|c|}
\hline $\begin{array}{c}\text { Study and Sample Program } \\
\text { Segments }\end{array}$ & Topics/Issues where Specific Recall Tested & $\begin{array}{c}\text { \% Listeners } \\
\text { Who Remember } \\
\text { Hearing Specific } \\
\text { Program Segments }\end{array}$ \\
\hline $\begin{array}{c}\text { (heard 1 of 5 sample segments) } \\
\text { (heard 1 of 5 sample segments) }\end{array}$ & $\begin{array}{l}\text { health care, diabetes, sexual behavior } \\
\text { sexual assault, services for low-income } \\
\text { families, community effects of drug and } \\
\text { alcohol abuse, tuberculosis, stress }\end{array}$ & $43 \%-68 \%$ \\
\hline $\begin{array}{c}\text { TCE/TVT-Local-KHDC } \\
\text { (1 of 5 sample segments) }\end{array}$ & $\begin{array}{l}\text { STD's, legal consequences of drunkenness, } \\
\text { stress in day to day life, diabetes, } \\
\text { cardiovascular diseases }\end{array}$ & $37 \%-59 \%$ \\
\hline $\begin{array}{c}\text { Kern Co. Prop. 10 } \\
\text { (heard 1 of 3 shows in each of 3 } \\
\text { thematic campaign strands) }\end{array}$ & $\begin{array}{l}\text { healthy pregnancy, infant care, parenting: } \\
\text { breast feeding, shaken baby syndrome, infant } \\
\text { dental care, fetal alcohol syndrome, teenage } \\
\text { pregnancy and services for teens, gestational } \\
\text { diabetes, disabled children services, child } \\
\text { abuse }\end{array}$ & $51 \%-58 \%$ \\
\hline $\begin{array}{c}\text { Kern Co. Prop 10 } \\
\text { (any 1 of 4 sample spots) }\end{array}$ & $\begin{array}{l}\text { CHDP, farmworker testimonials against child } \\
\text { abuse, dangers of tobacco in home, dangers of } \\
\text { alcohol in family life }\end{array}$ & \\
\hline \multicolumn{2}{|l|}{} \\
\hline
\end{tabular}

In addition to asking survey respondents in the TVT/TCE survey whether they had heard specific program segments, we elicited from them unprompted responses about "memorable" health-related programs $(Q .10-12$ series: Do you remember hearing health-related programming on Radio Bilingue? [If so] Was there any theme they dealt with which stands out in your mind? That is, a program which give you information you hadn't been aware of or which gave you a new way of thinking about health issues?). We tabulated these in thematic clusters to provide insights into listener interests and priorities. Three out of five listeners $(60 \%)$ were able to mention at least one theme/topic which stood out in their minds.

Looking at the patterns of listener responses regarding specific program segments which they remembered hearing and the unprompted responses there are a few conclusions which provide useful guidance in understanding the ways in which these multi-stranded campaigns affect their targeted audiences.

- The shows on sexuality and sexuallytransmitted diseases attract a good proportion of the station's regular listeners and are considered to be among the best shows in the cluster of TCE-funded programs we asked about — with higherthan-average approval ratings. These topics made up $13 \%$ of the "memorable topics" mentioned.

- In our analysis we clustered together "memorable topics" relating to children's health and parenting. This cluster made up $14 \%$ of the "memorable topics" mentioned. Within this cluster, topics relating to managing children's behavior and to family communications were very considered to be particularly important. They were also mentioned frequently in focus groups following up on surveys of Fresno and Tulare county parents of pre-school age children.

- Several of the shows which were recalled by less of the regular listeners (e.g., on diabetes - mentioned as a topic by $5 \%$ of the listeners, on drug and alcohol abuse mentioned by $7 \%$ ) seem to have engaged listeners for whom these health conditions or issues were a particular concern.

- The audiences for each specific thematic/topical strand include a range of "stakeholders" who are not themselves 
directly affected by the health conditions being addressed in the programming but who are concerned about the issue (usually because they believe it is relevant to a family member). Examples of such indirectly affected stakeholders include: parents of teenagers who are concerned about sexually-transmitted diseases, children of elderly parents with diabetes who are concerned about how to help their parents manage the disease.

- Shows which present concrete, practical information such as the El Centro show on clinic services for low-income families are more commonly recalled (e.g., by $68 \%$ of listeners) and more engaging than more abstract ones such as the Binational Health Week show focusing on the Mexican Minister of Health's vision of binational collaboration (e.g., the show recalled by only $33 \%$ of the listeners).

\section{Contributions to Family and Community Health Outcomes}

The survey data include notes from listeners' reports about how they had "used" the station's programming to improve their own or others' health. In contrast to the information typically conveyed in a doctor-patient discussion, where the emphasis may well be on individual issues, one of the groups of listeners finding Radio Bilingue's health information most useful are health intermediaries of one sort or another - a teacher, relative, co-worker, friend-who uses the information they have gotten from the station's programming to intervene in the lives of people they care about.

Thus, the station's function must be conceptualized not simply as being to directly inform listeners but also to catalyze discussion and dialogue. In addition to information on how programming catalyzed talks among parents and children, among friends and family relatives, we even heard a mayordomo's wife's report about how her husband turns the dial to Radio Bilingue's morning show when he takes farmworkers to the fields because he thinks its useful for them to hear on the way to work. Thus, one of the facets of the station's community service is its role in facilitating communication and serving to strengthen these predominantly immigrant communities' ability to mobilize their social capital to focus on and respond to health-related issues.

A case in point is that of a Linea Abierta show about the problems of older men going out with younger girls (aired as part of local programming on KSJV-Fresno in November, 2001). Survey respondents who remembered the programming and found it useful in their lives pointed to several different "uses" of this programming. One respondent, for example, said that a young woman in her family had been dating an older man and that the program had helped the respondent help this young relative. Another respondent said that the program had given him an opportunity to talk to his cousin who liked to date younger girls about this issue. Yet another listener said, "It helped me understand how one talks to those girls and the parents' rights to kick the guy out". A mother said it taught her and her husband how to better watch over what their 13 year-old daughter might be doing. In each of these cases, the utility of the programming stemmed not only from its ability to inform individuals who would benefit from the information but, also, from its ability to assist intermediaries in responding to problems/issues within their immediate social network - be it family or acquaintances.

Another Linea Abierta show about the importance of having a translator in a health care setting when one is needed (aired as part of KSJV's local programming in February, 2002) struck an interesting chord with Oaxacan immigrants and others who thought about the "use" of the program not so much in terms of getting a translator but as beginning to chose among health providers based on the provider's cultural competence. As one said, "Especially those of us who are Oaxacans who can't speak Spanish well, need to know where to go where they can serve us well...". Here the value of the station's programming stems not only from its immediate, direct role in informing listeners but, in a sense, of posing new possibilities such as the one that appears to have been emerging in these listeners' minds - that market forces might 
eventually serve to increase the availability of culturally responsive health care.

Listener comments on Radio Bilingue's programming on sexuality and sexuallytransmitted diseases utility for listeners is also instructive and, once again, underscores the diversity of "uses" of the health-related information. One respondent candidly said, "I learned how to be more responsible about raising my children. The show on STD's made me aware of the diseases I can get from sleeping around everywhere". Yet "technical" information is important also. One respondent said, "What I learned was to use protection and that HIV does not show up immediately" (an important factual point in thinking about responsible sexuality and the danger of infecting sexual partners). Another respondent's comments about programming on STD's shows the value of programs' providing a structure for otherwise-awkward discussions; a father said, "I learned some motivating information about how to talk with my boys about STD's and the high risk of their behavior". Another mother said the program had helped her begin talking more with her daughter about sex and that had led to better communication with her and that she was enjoying this improved communication.

There are some aspects of Radio Bilingue's broadcast service, where the programming moves beyond a purely informational role to catalyze family, neighborhood, and community dialogue. A female listener said she already knew about STD's but she thought the programming was useful because, "It lets men know they can't go running around and that even if they really want to have sex they need to be careful." Another woman said that the programming was useful to let people know that when men come to the U.S. without their wives and take up with women who are not their wives, then they can infect them when they go back home. The community radio environment provides a forum for this sort of mental and literal dialogue which is both public and "safe". What is interesting about this sort of case is that the impact of Radio Bilingue's programming stems, in part, from the its support for the propagation of healthy community values and strengthening of generally useful social norms. The more generally recognized "educational" value of the station's programming as an information conduit explains only part of the impact. The function of the host-guest dialogue in the talk show format, of the persona/witness' personal story in the testimonial format, for example, serve not simply to inform but to set in motion a cascade of developments - including acquisition information, attitudinal change, changed aspirations, and changed behavior.

Another program which several listeners described as having immediate utility for them was the program on childhood obesity and diabetes and the overall risk factors for diabetes. One group who benefited from this programming included persons for whom the program was directly relevant, e.g. a listener who said the programming was important to him because he is an overweight diabetic, a woman who knows she is a borderline diabetic and who listened very closely to the program (and others) so she can learn what she needs to do to take care of herself. However, a different use emerged among those who found the information generally (e.g., "not to drink so many sodas") or in talking to their children with a number of parents saying straightforwardly that their children were overweight so they had paid careful attention to the programming.

Among the survey respondents were two teachers - both of whom, in reflecting on what they got out of Radio Bilingue's health-related programs, said they relied on it for teaching their students. However, the particular value of the programming was different for each. One of these teachers said, "I'm very well informed on many of the issues but I get new perspectives and information on new topics by listening". The other said, "I take a lot of the information and pass it on, both to the people I know and my students".

The data on utility of the programming suggest that there is value not only to programming on topics of high priority to the community but, also, on topics of great importance to smaller sub-populations. For example, one survey 
respondent, commenting on a local show about ways Mexican health professionals could get their licenses re-confirmed in California (a local showed aired on KSJV-Fresno in January, 2002), said, "I studied in Mexico but without knowing the language here, I didn't know how to get worked hear but after hearing the program, I learned where to go." Another listener said the programming had been useful to him in thinking about how to build on the body of knowledge he already had-in veterinary medicine - to find more rewarding employment in California

\section{Conclusions}

The audience research on Radio Bilingue's ability to reach and engage low-literate limitedEnglish audiences who are not easily reached by print materials or other health promotion strategies confirms the utility of Spanishlanguage radio as a cost-effective medium for efforts to improve health awareness, positively impact health-related attitudes, strengthen aspirations, and promote healthy behaviors.

The efficacy of Radio Bilingue's health promotion efforts stems in part from its ability to replicate in a virtual agora the sort of personal relationship, the sense of confianza, which makes the work of face-to-face campaigns relying on grassroots promotoras work so well. The impact of the station's health promotion campaigns is not because it is a "media vehicle" which can effectively deliver accurate and relevant information but, rather, because it has managed to develop communication strategies to engage its listeners in thinking and talking seriously and energetically about how to improve their health and the health of others they care about.

Our findings regarding the extent to which listeners discuss health topics they have heard on the radio with family members and others and, in the process, re-formulate and re-phrase the messages suggest that traditional models about "delivering" information to populations which must be "educated" as the primary mechanism for health promotion should be revised to give greater emphasis to the role of media sources as catalysts for sparking community dialogue.

New insights stemming from small-world theory, namely the effects of introducing sublinks in networks to increase clustering (Buchanan, 2002; Gladwell, 2000) suggest that further attention to designing messages which are tailored to appeal to identified sub-groups of listeners will enhance the station's ability to prime and sustain community dialogue for health. A key element in such a strategy will be to build listeners' propensity to discuss programming themes with family, friends, and co-workers. Listeners' reports about how they currently "use" Radio Bilingue programming provide useful guidance about how to develop programming which will engage targeted audience segments. The use of media to assist immigrant communities to better draw down on their store of social capital as a resource for improving the well-being of economically disadvantaged communities is one of the few rays of hope as the socioeconomic gap between Latino immigrants and native-born populations continues to widen and funding for direct service provision is threatened.

\section{References}

Arbitron. (2002). 2001 hispanic radio today.

Buchanan, M. (2002). Nexus. W. W. Norton and Co..

Fix, M., \& Zimmerman, W. (1999). All under one roof: Mixed-status families in an era of reform. Washington, DC: Urban Institute.

Gladwell, M. (2000). The tipping point. NY: Little, Brown, and Co.

Kissam, E., \&Jacobs, I. (2002). Undercount of indigenous-origin Mexican immigrants in rural California in census 2000: Strategies for community-based research to improve the distorted picture. Paper prepared for UC Santa Cruz Conference, September, 2002.

Kissam, E., Gabbard, S., and Martin, P. (1993). The impact of migrant travel patterns on the undercount of Hispanic farm workers. Proceedings of the Bureau of the Census Research Conference on 
Undercounted Ethnic Populations, Richmond, VA, May, 1993.

Rosenau, J. N. (1993). Coherent connection or commonplace contiguity. In Abraham F. Lowenthal and Katrina Burgess (Eds.), The California-Mexico connection. Stanford, CA: Stanford University Press.

\section{Acknowledgements}

We would like to acknowledge the hard work, patience, and skill of our team of remate interviewers Rafael Flores, Natalie Orozco, Jorge San Juan, and Marco Santiago - throughout the long hot summer of 2002.

This research was conducted under contract with Radio Bilingue with project funding support from The California Endowment and from the Tobacco Tax Health Protection Act of 1988-Proposition 99, under Grant \#01-15510 with the California Department of Health Services, Tobacco Control Section.

\section{Author Information}

Edward Kissam*

Jo Ann Intili

Anna Garcia

Radio Bilingue

4810 Trinidad Ave.

Oakland, CA 94602

(510) 482-9979

E-Mail: ekissam@aiweb.com

E-Mail: ekissam@pacbell.net

* Corresponding author 